\title{
Acute kidney injury due to thin basement membrane disease mimicking Deferasirox nephrotoxicity: a case report
}

Keiko Oda, Kan Katayama* ${ }^{*}$, Akiko Tanoue, Tomohiro Murata, Yumi Hirota, Shoko Mizoguchi, Yosuke Hirabayashi, Takayasu Ito, Eiji Ishikawa, Kaoru Dohi and Masaaki Ito

\begin{abstract}
Background: Although the renal toxicity of Deferasirox, an oral iron chelator, has been reported to be mild, there have been reports of acute interstitial nephritis or Fanconi syndrome due to this agent. Thin basement membrane disease (TBMD) is a hereditary disease characterized primarily by hematuria, with gross hematuria also observed in about 7\% of cases. We herein report a case of TBMD that presented with acute kidney injury and gross hematuria during treatment with Deferasirox.

Case presentation: The patient was a 63-year-old man who had been diagnosed with myelodysplastic syndrome 6 years ago. He had started taking Deferasirox at $125 \mathrm{mg}$ due to post-transfusion iron overload 6 months ago. Deferasirox was then increased to $1000 \mathrm{mg}$ three months ago. When the serum creatinine level increased, Deferasirox was reduced to $500 \mathrm{mg}$ three weeks before hospitalization. Although the serum creatinine level decreased once, he developed a fever and macroscopic hematuria one week before hospitalization. The serum creatinine level increased again, and Deferasirox was stopped four days before hospitalization. He was admitted for the evaluation of acute kidney injury and gross hematuria. Treatment with temporary hemodialysis was required, and a kidney biopsy was performed on the eighth day of admission. Although there was no major abnormality in the glomeruli, the leakage of red blood cells into the Bowman's space was observed. Erythrocyte cast formation was observed in the tubular lumen, which was associated with acute tubular necrosis. The results of an electron microscopic study were compatible with TBMD.
\end{abstract}

Conclusion: Although Deferasirox is known to be nephrotoxic, gross hematuria is relatively rare. When we encounter a case of acute kidney injury with gross hematuria during treatment with Deferasirox, TBMD should be considered as a possible cause of gross hematuria.

Keywords: Acute kidney injury, Deferasirox - gross hematuria - myelodysplastic syndrome - thin basement membrane disease

\section{Background}

Deferasirox is an oral iron chelator used for treating chronic iron overload in transfused hematologic patients, such as those with thalassemia major and myelodysplastic syndrome (MDS). Although the renal toxicity of Deferasirox is reportedly mild [1], there have been reports of acute interstitial nephritis or Fanconi syndrome due to this agent [2-11].

\footnotetext{
* Correspondence: katayamk@clin.medic.mie-u.ac.jp

Department of Cardiology and Nephrology, Mie University Graduate School of Medicine, 2-174 Edobashi, Tsu, Mie 514-8507, Japan
}

Thin basement membrane disease (TBMD) is a hereditary disease thought to be caused by heterozygous mutations in COL4A3 or COL4A4. Although microscopic hematuria is characteristic of TBMD and the clinical course of TBMD is good, gross hematuria is also observed in about $7 \%$ of cases [12].

We herein report a case of TBMD that presented with acute kidney injury and gross hematuria during treatment with Deferasirox.

(c) The Author(s). 2018 Open Access This article is distributed under the terms of the Creative Commons Attribution 4.0 International License (http://creativecommons.org/licenses/by/4.0/), which permits unrestricted use, distribution, and 


\section{Case presentation}

The patient was a 63-year-old man who had neither microscopic nor macroscopic hematuria at his previous medical checkup. There was no apparent family history of kidney disease. His leukocyte and platelet counts had begun to decrease 6 years ago, and he was diagnosed with myelodysplastic syndrome (MDS) by bone marrow aspiration. He started treatment for anemia with blood transfusion 2 years ago. He was not on any antiplatelet or anticoagulant medications and his serum creatinine $(\mathrm{Cr})$ level was $0.74 \mathrm{mg} / \mathrm{dL} 9$ months previously. He started taking the oral iron chelator Deferasirox at $125 \mathrm{mg}$ due to post-transfusion iron overload 6 months ago. The dosage was then increased to $1000 \mathrm{mg} 3$ months ago. When the serum $\mathrm{Cr}$ level increased, the Deferasirox dosage was reduced to $500 \mathrm{mg} 3$ weeks before hospitalization. Although the serum $\mathrm{Cr}$ level decreased once, he developed a fever and macroscopic hematuria 1 week before hospitalization. The serum $\mathrm{Cr}$ level increased again, and Deferasirox was stopped 4 days before hospitalization. He was admitted urgently to our hospital for the evaluation of acute kidney injury and macroscopic hematuria.

On admission, his body temperature was $36.7{ }^{\circ} \mathrm{C}$, and his heart rate was 81 per minute. His blood pressure was 125/64 mmHg. A physical examination revealed no ab normalities except for anemic palpebral conjunctiva. The laboratory values at the time of hospitalization are shown in Table 1. Pancytopenia was noted, and the coagulation values were within the respective normal ranges. The blood urea nitrogen and serum $\mathrm{Cr}$ levels were 42.0 and $3.97 \mathrm{mg} / \mathrm{dL}$, respectively. The serum ferritin level was high at $14230 \mathrm{ng} / \mathrm{mL}$. A urinalysis showed proteinuria and hematuria, and a urinary sediment analysis revealed more than 100 dysmorphic red blood cells (RBCs) per high-power field with epithelial casts, granular casts, and RBC casts. The urinary protein -to-creatinine ratio was $1.20 \mathrm{~g} / \mathrm{gCr}$. Urinary $\mathrm{N}$-acetyl - $\beta$-D-glucosaminidase and $\beta_{2}$ microglobulin values were $18.4 \mathrm{~g} / \mathrm{gCr}$ and $2757 \mu \mathrm{g} / \mathrm{L}$, respectively. The myeloperoxidase-antineutrophil cytoplasmic antibody (MPOANCA), proteinase-3-ANCA, anti-glomerular basement membrane (GBM) antibody, antinuclear antibody, and anti-streptolysin $\mathrm{O}$ were all negative.

After hospitalization, the patient was treated with intravenous administration of $500 \mathrm{mg}$ of methylprednisolone for 3 consecutive days, followed by $30 \mathrm{mg}$ of prednisolone per day orally. Hemodialysis therapy was initiated due to oliguria and discontinued after 10 days because his urine volume recovered. A kidney biopsy was performed on the eighth day of admission.

One of 11 glomeruli was globally sclerotic. None of glomeruli showed crescentic formation or adhesion. Although there were no major abnormalities in the glomeruli (left-upper panel, Fig. 1a), the leakage of RBCs into the Bowman's space was observed (inset of leftupper panel, Fig. 1a). An electron micrograph showed leakage of red blood cells, two of which were dysmorphic, into Bowman's space (right-upper panel, Fig. 1a). Interstitial fibrosis with acute tubular necrosis were observed in approximately $40 \%$ of the total area (lower panel, Fig. 1a). Erythrocyte cast formation was observed in the tubular lumen, which was associated with tubular simplification (Fig. 1b). There were positive blue signals both in glomerular cells and Bowman's capsular epithelial cells on Berlin blue staining, which was reflected glomerular hemorrhaging (left-upper panel, Fig. 2a). The positive blue signals were prominent in the tubular cells (right-upper panel, Fig. 2a). There were no apparent positive blue signals in the normal human kidney sections, which were purchased from Zyagen (HP-901, CA, USA) (lower panels, Fig. 2a). There was no significant staining for immunoglobulin G (IgG), IgA, IgM, complement 3 (C3), C1q, or fibrinogen.

Since there were no signs of rapidly progressive glomerulonephritis on a kidney biopsy, the amount of prednisolone after the second round of the intravenous administration of $500 \mathrm{mg}$ of methylprednisolone for 3 consecutive days was decreased. Although the macroscopic hematuria disappeared at 2 weeks after admission, the serum Cr level was $1.92 \mathrm{mg} / \mathrm{dL}$ at the time of discharge and was unchanged after 2 months. The results of the electron microscopic study revealed thinning of the GBM without any immune complexes (Fig. 2b). The thickness of the average GBM was $199 \pm 47 \mathrm{~nm}$, which was consistent with TBMD. Therefore, a genomic sequence analysis of the COL4A3 and COL4A4 genes was performed by Sanger sequencing method after purifying the polymerase chain reaction products of exons, and five and six missense mutations were found in COL4A3 and COL4A4, respectively (Table 2).

\section{Discussion and conclusion}

We encountered a patient who presented with acute kidney injury and gross hematuria during treatment with Deferasirox, which was used for transfusion-related iron overload due to MDS. A kidney biopsy revealed glomerular hemorrhaging and erythrocyte cast formation in the tubular lumen, which was associated with tubular simplification and acute tubular necrosis. An electron microscopic study revealed thinning of the GBM without any immune complexes, so the patient was diagnosed with TBMD.

Renal injury due to Deferasirox includes acute tubulointerstitial nephritis as well as Fanconi syndrome [211]. However, there has only been one report of mild microscopic hematuria [2], and gross hematuria as a side effect of Deferasirox is considered unlikely [13]. The present case showed progressive kidney injury despite 
Table 1 The laboratory data on admission

\begin{tabular}{|c|c|c|}
\hline Parameter & Patient value & Reference \\
\hline \multicolumn{3}{|l|}{ Urinalysis } \\
\hline $\mathrm{pH}$ & 5.5 & $4.5-7.5$ \\
\hline Protein (g/gCr) & 1.2 & $<0.15$ \\
\hline Occult blood & $3+$ & $(-)$ \\
\hline Dysmorphic red blood cells (/HPF) & $>100$ & $<5$ \\
\hline Epithelial casts (MF) & $20-29$ & $(-)$ \\
\hline Granular casts (MF) & $20-29$ & $(-)$ \\
\hline Red blood cell casts (MF) & $1-4$ & $(-)$ \\
\hline N-acetyl--D-glucosaminidase (U/gCr) & 18.4 & $<5.6$ \\
\hline$\beta 2$ microglobulin ( $\mu \mathrm{g} / \mathrm{L})$ & 2757 & $<150$ \\
\hline \multicolumn{3}{|l|}{ Hematology } \\
\hline White blood cell count $(/ \mu \mathrm{L})$ & 2070 & $3300-8600$ \\
\hline Neutrophils (\%) & 59.0 & $48.0-61.0$ \\
\hline Red blood cells $\left(\times 10^{4} / \mu \mathrm{L}\right)$ & 240 & $435-555$ \\
\hline Hemoglobin (g/dL) & 7.4 & $13.7-16.8$ \\
\hline Hematocrit (\%) & 22.8 & $40.7-50.1$ \\
\hline Platelet count $\left(\times 10^{4} / \mu \mathrm{L}\right)$ & 11.4 & $15.8-34.8$ \\
\hline \multicolumn{3}{|l|}{ Coagulation } \\
\hline Activated partial thromboplastin time (seconds) & 27.7 & $<37.0$ \\
\hline Prothrombin time (seconds) & 12.8 & $9.8-12.1$ \\
\hline Prothrombin time international normalized ratio & 1.11 & $0.88-1.08$ \\
\hline Fibrinogen (mg/dL) & 660 & $200-400$ \\
\hline \multicolumn{3}{|l|}{ Blood chemistry } \\
\hline Total protein (g/dL) & 6.5 & $6.6-8.1$ \\
\hline Albumin (g/dL) & 3.6 & $4.1-5.1$ \\
\hline Blood urea nitrogen (mg/dL) & 42.0 & $8.0-20.0$ \\
\hline Creatinine (mg/dL) & 3.97 & $0.65-1.07$ \\
\hline Lactic dehydrogenation enzyme (U/L) & 384 & $124-222$ \\
\hline Uric acid (mg/dL) & 8.9 & $3.7-7.8$ \\
\hline Natrium (mmol/L) & 137 & $138-145$ \\
\hline Potassium (mmol/L) & 5.1 & $3.6-4.8$ \\
\hline Chlorine (mmo/L) & 101 & $101-108$ \\
\hline Calcium (mg/dL) & 9.2 & $8.8-10.1$ \\
\hline Inorganic phosphates (mg/dL) & 3.9 & $2.7-4.6$ \\
\hline Bicarbonate ion (mmol/L) & 22 & $22-32$ \\
\hline C-reactive protein (mg/dL) & 5.12 & $<0.14$ \\
\hline $\mathrm{Fe}(\mu \mathrm{g} / \mathrm{dL})$ & 171 & $40-188$ \\
\hline Total iron-binding capacity $(\mu \mathrm{g} / \mathrm{dL})$ & 221 & $253-365$ \\
\hline Ferritin (ng/mL) & 14,230 & $50.0-200.0$ \\
\hline
\end{tabular}

the cessation of Deferasirox, and the presence of gross hematuria with dysmorphic RBCs and RBC casts in the urine sediment could not be explained by toxicity due to Deferasirox alone, since there was no evidence of acute tubulointerstitial nephritis in the renal interstitium.
Since the serum ferritin level was high and there was deposition of hemosiderin in both podocytes and Bowman's epithelial cells in the present case, we considered the possibility of iron overload nephropathy. However, gross hematuria is reportedly rare, although 


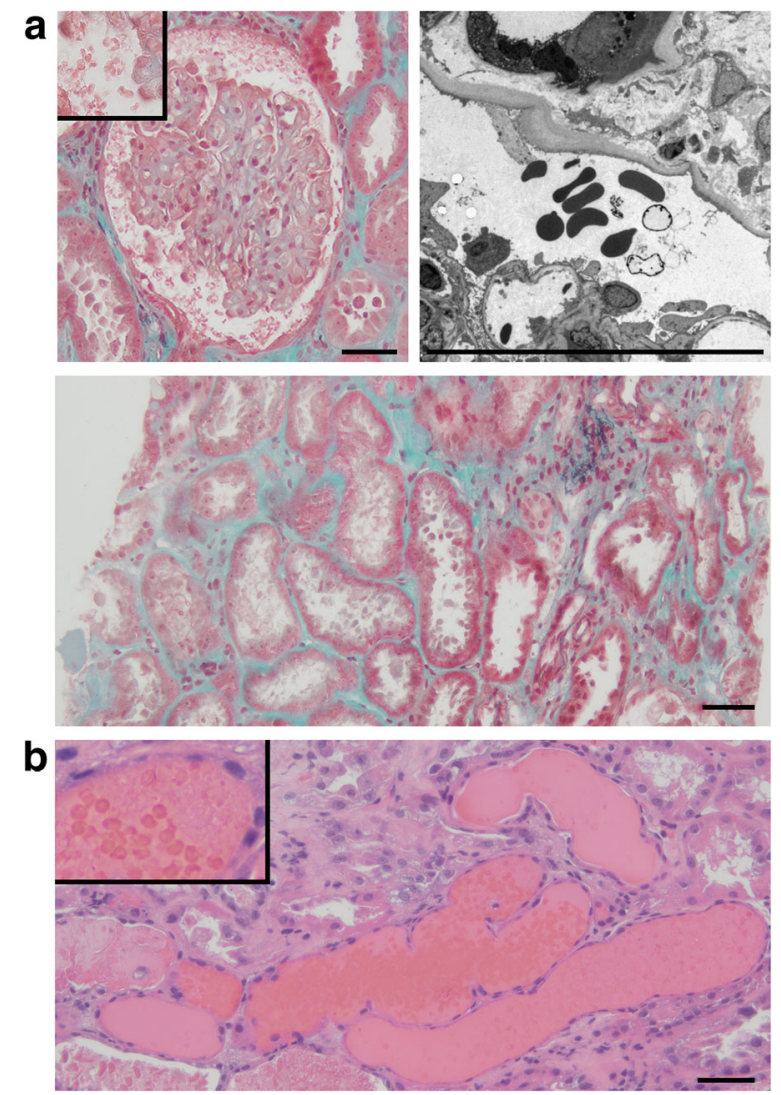

Fig. 1 a Although there were no major abnormalities in the glomeruli (left-upper panel), the leakage of red blood cells into the Bowman's space was observed (Masson Trichrome staining; the inset of left-upper panel). An electron micrograph showed the leakage of red blood cells, two of which were dysmorphic, into Bowman's space (right-upper panel). Tubulointerstitial fibrosis with acute tubular necrosis was detected (Masson Trichrome staining; lower panel). b Massive erythrocyte cast formation was observed in the tubular lumen and the inset denoted red blood cells in Hematoxylin and eosin staining. Scale bars, $50 \mu \mathrm{m}$

proteinuria has been observed in an iron-overload rat model [14].

There were many $R B C$ casts in the tubules, and the leakage of RBC cells into the Bowman's space was observed. Therefore, we considered that the RBC casts might have caused acute tubular necrosis and subsequent acute kidney injury. Chronic interstitial fibrosis was thought to be due to age-related change, since the patient was neither hypertensive nor diabetic. The deposition of hemosiderin in both podocytes and Bowman's epithelial cells was thought to be the result of glomerular hemorrhaging. There has been a report of acute kidney injury with gross hematuria [15], including IgA and warfarin-related nephropathy. The injury was thought to have been caused by not only the increased intratubular pressure due to the obstruction of RBC casts, but also due to the influence of heme-induced oxidative damage [15].

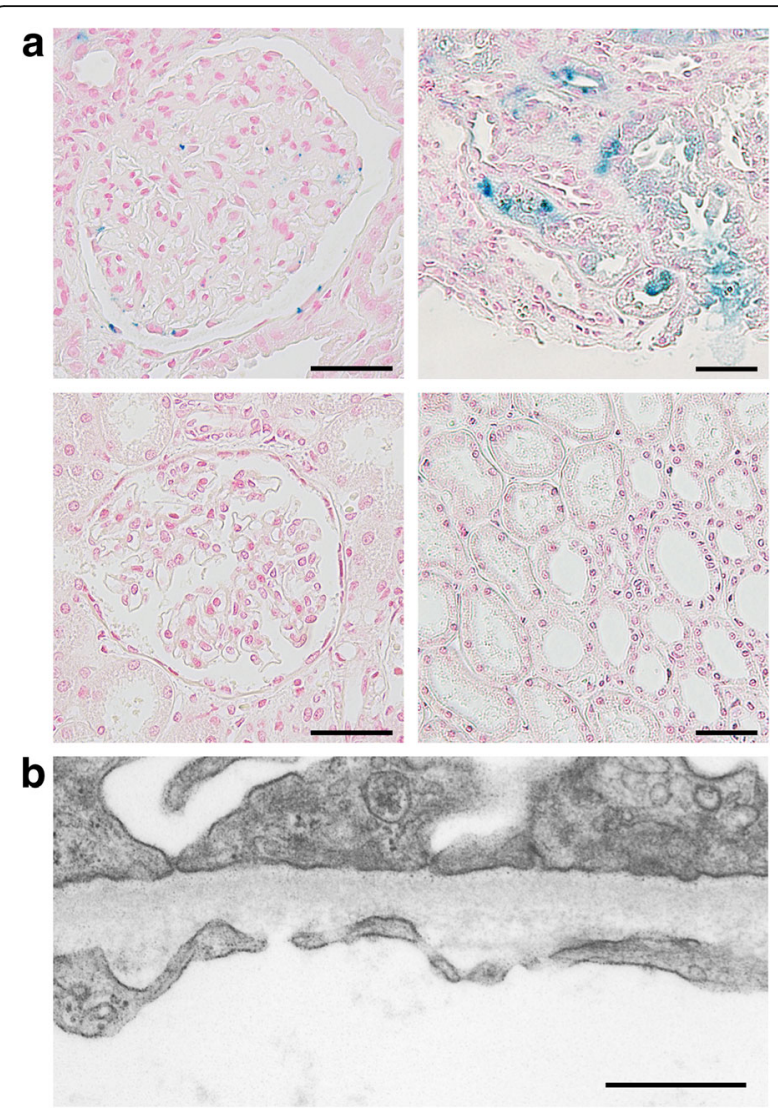

Fig. 2 a There were positive blue signals in both the glomerular cells and Bowman's capsular epithelial cells in Berlin blue staining (left-upper panel). The positive blue signals were prominent in the tubular cells (right-upper panel). There were no apparent positive blue signals in the normal human kidney sections (lower panels). Scale bars, $50 \mu \mathrm{m}$. b The results of an electron microscopic study revealed the thinning of the glomerular basement membrane without any immune complexes. Scale bar, $500 \mathrm{~nm}$
Table 2 The results of the genomic sequence analysis

\begin{tabular}{|c|c|c|c|}
\hline \multicolumn{4}{|l|}{ COL4A3 } \\
\hline c. $127 G>C$ & p.G43R & heterozygous & benign \\
\hline c. $422 \mathrm{~T}>\mathrm{C}$ & p.L141P & homozygous & benign \\
\hline c. $485 A>G$ & p.E162G & homozygous & benign \\
\hline C. $805 G>A$ & p.E269K & heterozygous & benign/likely benign \\
\hline c. $1721 C>T$ & p.P574L & heterozygous & benign \\
\hline \multicolumn{4}{|l|}{ COL4A4 } \\
\hline c.839T > G & p.M280R & heterozygous & unreported \\
\hline c. $1444 C>T$ & p.P482S & heterozygous & benign \\
\hline c. $2656 C>A$ & p.L886l & heterozygous & synonymous \\
\hline c. $3011 C>T$ & p.P1004L & heterozygous & benign \\
\hline c.3979G > A & p.V1327 M & homozygous & benign \\
\hline c. $4207 \mathrm{~T}>\mathrm{C}$ & p.S1403P & homozygous & benign \\
\hline
\end{tabular}




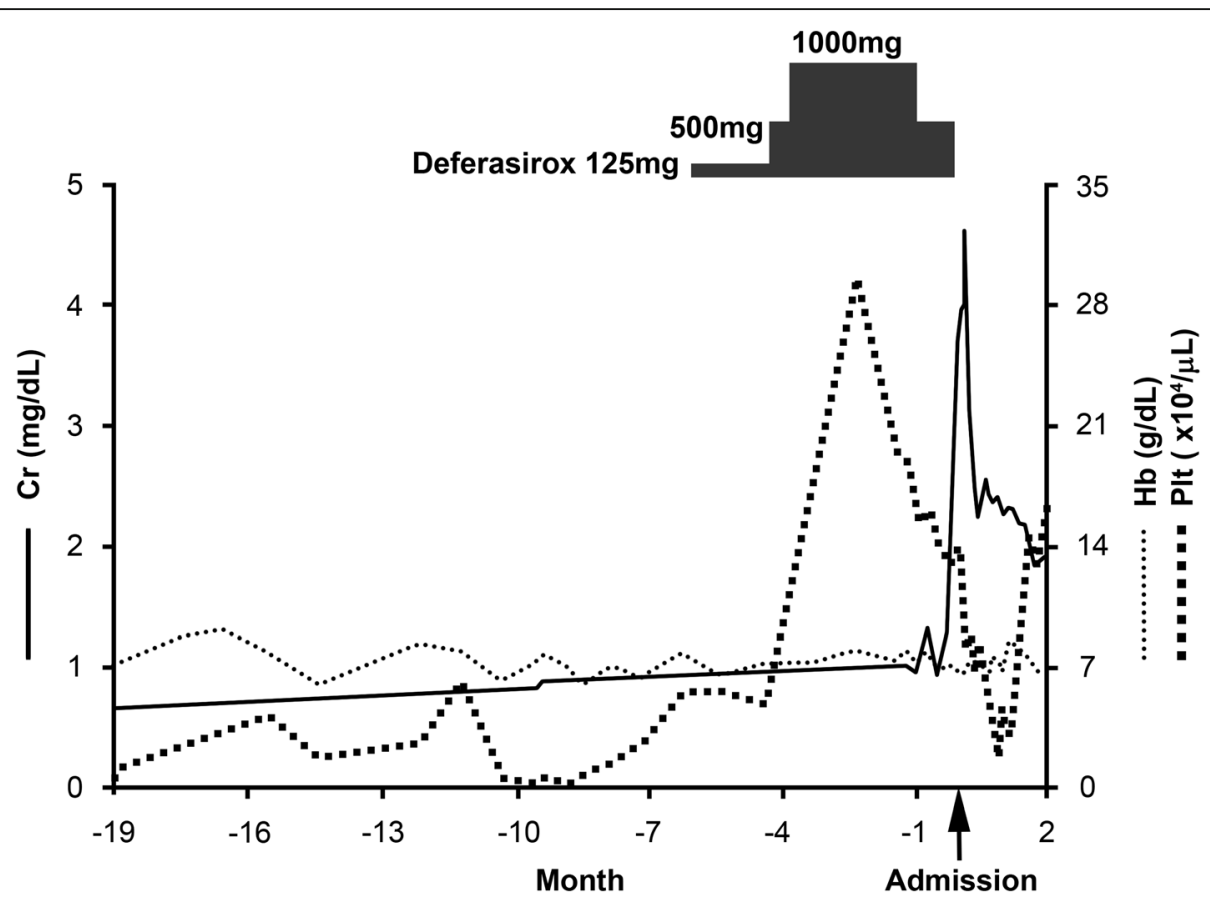

Fig. 3 The clinical course. Admission (month 0). Cr; serum creatinine, Hb; hemoglobin, Plt; platelet

The GBM of the present case was less than $250 \mathrm{~nm}$, so we diagnosed the patient with TBMD. Furthermore, a genetic analysis of the COL4A3 and COL4A4 genes revealed five and six missense mutations, respectively. Two mutations, c.839 T > G (p.M280R) and c.2656C > A (p.L886I) in COL4A4, were unreported, while nine mutations were reported to be benign in the Leiden Open Variation Database or ClinVar (Table 2). Although c.2656C > A (p.L886I) in COL4A4 seemed to be a synonymous mutation, c.839 T > G (p.M280R) in COL4A4 has never been reported (submission code \#00206809 in LOVD mutation database) and may be related to the onset of TBMD. However, c.839 T > G (p.M280R) in COL4A4 was predicted to be "benign" in the program PolyPhen-2 while it was predicted to be "not tolerated" at Seq Rep 0.45 in the Sorting Intolerant From Tolerant (SIFT) software program. Since the mutation resides in the triple-helical collagenous domain of type IV collagen $\alpha 4$ chain, its phe notype might be milder than that of the glycine mutation that appears in every three amino acids in the collagenous domain. There were also reports that TBMD progression might be associated with other modifier genes [16-20].

Gross hematuria is reported to occur in around $7 \%$ of adult TBMD patients [12]. However, loin pain hematuria syndrome was unlikely because there was no sign of lumbago. Although the patient had no coagulation disorders, thrombocytopenia due to MDS was noted (its nadir was $0.1 \times 10^{4} / \mu \mathrm{L}$, Fig. 3), which might have affected the predisposition to glomerular hemorrhaging under conditions of TBMD in the present case. The macroscopic hematuria in the present case did not occur when the thrombocytopenia was at its nadir, which might imply that an unknown mechanism-other than thrombocytopenia-was involved in the development of macroscopic hematuria. There was a report that described TBMD and acute kidney injury due to gross hematuria and tubular necrosis in a patient on warfarin therapy [21]. Another report described a case of TBMD and throm bocytopenia [22].

Since his renal function deteriorated rapidly and he had a fever, we suspected the patient had ANCA-associated vasculitis or post-infectious glomerulonephritis, and treatment with intravenous methylprednisolone was initiated. However, there was no evidence of crescent formation or mesangial proliferation in the glomeruli. This patient may have had some unknown infection rather than vasculitis because leukocytopenia due to MDS was observed.

Although Deferasirox is known to be nephrotoxic, gross hematuria is relatively rare. When we encounter a case of acute kidney injury with gross hematuria during treatment with Deferasirox, TBMD can be considered to be a cause of gross hematuria.

\section{Abbreviations}

C3: Complement 3; Cr: Creatinine; GBM: Glomerular basement membrane; IgG: Immunoglobulin G; MDS: Myelodysplastic syndrome; MPO-

ANCA: Myeloperoxidase-antineutrophil cytoplasmic antibody; RBC: Red blood cells; WF: Whole-field

Acknowledgements Not applicable. 


\section{Funding}

Not applicable.

\section{Availability of data and materials}

The datasets used and/or analyzed during the current study are available from the corresponding author on reasonable request.

\section{Authors' contributions}

$\mathrm{KO}, \mathrm{KK}, \mathrm{AT}, \mathrm{TM}$, and $\mathrm{YuH}$ participated in the acquisition of clinical data. KO, $\mathrm{KK}, \mathrm{AT}, \mathrm{SM}, \mathrm{YOH}, \mathrm{TI}, \mathrm{El}, \mathrm{KD}$, and Ml carried out the histological examination and interpretation. $\mathrm{KO}$ and $\mathrm{KK}$ wrote a draft of the manuscript, and AT, TM, $\mathrm{YuH}, \mathrm{SM}, \mathrm{YoH}, \mathrm{TI}, \mathrm{El}, \mathrm{KD}$, and Ml revised it critically. All authors read and approved the final manuscript.

\section{Ethics approval and consent to participate} Not applicable.

\section{Consent for publication}

Written informed consent was obtained from the patient for the publication of this case report. A copy of the written consent is available for review by the editor of this journal.

\section{Competing interests}

M.I. received departmental scholarship funds of $\geq 1,000,000$ yen per year for direct expenses from MSD K.K., Bristol-Myers Squibb, BIOTORONIK JAPAN, Inc., Astellas Pharma Inc., Shionogi \& Co., Ltd., and Otsuka Pharmaceutical Co., Ltd., in 2015, MSD K.K., Astellas Pharma Inc., Takeda Pharmaceutical Company, Ltd., Daiichi Sankyo Company, Ltd., and Otsuka Pharmaceutical Co., Ltd., in 2016, and MSD K.K., Shionogi \& Co., Otsuka Pharmaceutical Co., Ltd., Takeda Pharmaceutical Company, Ltd., and Daiichi Sankyo Company, Ltd., in 2017. The companies associated with this funding were not involved in the manuscript preparation or the decision to publish the present case report. All other authors have no competing interest to declare.

\section{Publisher's Note}

Springer Nature remains neutral with regard to jurisdictional claims in published maps and institutional affiliations.

\section{Received: 28 August 2018 Accepted: 10 December 2018} Published online: 17 December 2018

\section{References}

1. Cappellini MD, Cohen A, Piga A, Bejaoui M, Perrotta S, Agaoglu L, et al. A phase 3 study of deferasirox (ICL670), a once-daily oral iron chelator, in patients with beta-thalassemia. Blood. 2006;107:3455-62.

2. Brosnahan G, Gokden N, Swaminathan S. Acute interstitial nephritis due to deferasirox: a case report. Nephrol Dial Transplant. 2008;23:3356-8.

3. Yusuf B, McPhedran P, Brewster UC. Hypocalcemia in a dialysis patient treated with deferasirox for iron overload. Am J Kidney Dis. 2008;52:587-90.

4. Rafat C, Fakhouri F, Ribeil JA, Delarue R, Le Quintrec M. Fanconi syndrome due to deferasirox. Am J Kidney Dis. 2009;54:931-4.

5. Even-Or E, Becker-Cohen R, Miskin H. Deferasirox treatment may be associated with reversible renal Fanconi syndrome.1. Am J Hematol. 2010; 85:132-4.

6. Grangé S, Bertrand DM, Guerrot D, Eas F, Godin M. Acute renal failure and Fanconi syndrome due to deferasirox. Nephrol Dial Transplant. 2010;25:2376-8.

7. Yew CT, Talaulikar GS, Falk MC, Clayton P, D'Rozario J, Brown M. Acute interstitial nephritis secondary to deferasirox causing acute renal injury needing short-term dialysis. Nephrology (Carlton). 2010;15:377.

8. Rheault MN, Bechtel H, Neglia JP, Kashtan CE. Reversible Fanconi syndrome in a pediatric patient on deferasirox. Pediatr Blood Cancer. 2011;56:674-6.

9. Wei HY, Yang CP, Cheng CH, Lo FS. Fanconi syndrome in a patient with $\beta$ thalassemia major after using deferasirox for 27 months. Transfusion. 2011; 51:949-54.

10. Murphy N, Elramah M, Vats H, Zhong W, Chan MR. A case report of deferasirox-induced kidney injury and Fanconi syndrome. WMJ. 2013; 112:177-80.

11. Shah L, Powell JL, Zaritsky JJ. A case of Fanconi syndrome due to a deferasirox overdose and a trial of plasmapheresis. J Clin Pharm Ther. 2017; 42:634-7.
12. Savige J, Rana K, Tonna S, Buzza M, Dagher H, Wang YY. Thin basement membrane nephropathy. Kidney Int. 2003;64:1169-78.

13. Díaz-García JD, Gallegos-Villalobos A, Gonzalez-Espinoza L, Sanchez-Niño MD, Villarrubia J, Ortiz A. Deferasirox nephrotoxicity-the knowns and unknowns. Nat Rev Nephrol. 2014;10:574-86.

14. Richter GW. Iron overload nephropathy in rats. Pathol Res Pract. 1980; 168:84-106.

15. Moreno JA, Martín-Cleary C, Gutiérrez E, Toldos O, Blanco-Colio LM, Praga $\mathrm{M}$, et al. AKI associated with macroscopic glomerular hematuria: clinical and pathophysiologic consequences. Clin J Am Soc Nephrol. 2012;7:175-84.

16. Voskarides K, Pierides A, Deltas C. COL4A3/COL4A4 mutations link familial hematuria and focal segmental glomerulosclerosis. Glomerular epithelium destruction via basement membrane thinning? Connect Tissue Res. 2008;49:283-8.

17. Tonna S, Wang YY, Wilson D, Rigby L, Tabone T, Cotton R, et al. The R229Q mutation in NPHS2 may predispose to proteinuria in thin-basementmembrane nephropathy. Pediatr Nephrol. 2008;23:2201-7.

18. Pierides A, Voskarides K, Kkolou M, Hadjigavriel M. Deltas C. X-linked, COL4A5 hypomorphic Alport mutations such as G624D and P628L may only exhibit thin basement membrane nephropathy with microhematuria and late onset kidney failure. Hippokratia. 2013;17:207-13.

19. Stefanou C, Pieri M, Savva I, Georgiou G, Pierides A, Voskarides K, et al. Coinheritance of functional Podocin variants with heterozygous collagen IV mutations predisposes to renal failure. Nephron. 2015;130:200-12.

20. Voskarides K, Stefanou C, Pieri M, Demosthenous P, Felekkis K, Arsali M, et al. A functional variant in NEPH3 gene confers high risk of renal failure in primary hematuric glomerulopathies. Evidence for predisposition to microalbuminuria in the general population. PLoS One. 2017;12:e0174274.

21. Abt $A B$, Carroll LE, Mohler JH. Thin basement membrane disease and acute renal failure secondary to gross hematuria and tubular necrosis. Am J Kidney Dis. 2000;35:533-6.

22. Lim AK, Brown S, Simpson I, Dowling JP. Acute kidney injury due to glomerular haematuria and obstructive erythrocyte casts associated with thrombocytopaenia and thin basement membrane disease: a case report. BMC Nephrol. 2015;16:180

\section{Ready to submit your research? Choose BMC and benefit from:}

- fast, convenient online submission

- thorough peer review by experienced researchers in your field

- rapid publication on acceptance

- support for research data, including large and complex data types

- gold Open Access which fosters wider collaboration and increased citations

- maximum visibility for your research: over $100 \mathrm{M}$ website views per year

At BMC, research is always in progress.

Learn more biomedcentral.com/submissions 